\title{
Are women safe in disaster? Competency in handling gender-based violence by public health staff in Galle district
}

\author{
De Silva EPM ${ }^{1}$, Ponnamperuma T T ${ }^{2}$ \\ ${ }^{1}$ Postgraduate Institute of Medicine, University of Colombo, Colombo, Sri Lanka. \\ ${ }^{2}$ Department of Community Medicine, Faculty of Medicine, University of Ruhuna, Galle, Sri Lanka.
}

Correspondence: Dr. Thyagi Ponnamperuma

e-mail: thaygi p@yahoo.com

https://orcid.org/0000-0002-0031-3483

Submitted on 14.09.2020 and accepted for publication on 07.11.2020

\begin{abstract}
Introduction: Gender-based violence (GBV) is a human right issue that is common but under reported. It is noted that GBV incidence increases in disaster situations. As the public health staff is the key responsible personnel in post-disaster health management, their competencies in managing GBV in crisis situation are extremely important.

Methods: A descriptive cross-sectional study was conducted in conveniently selected 8 Medical Officer of Health $(\mathrm{MOH})$ areas in Galle district. All four categories of public health workers (medical officers, nursing sisters, public health inspectors and midwives) working at selected $\mathrm{MOH}$ offices were assessed by a selfadministrated questionnaire regarding knowledge on identification, prevention and management of GBV victims in disaster situations.

Results: Among 200 public health workers, only $23.5 \%$ had training on disaster management. Among the trained MOH staff, only $34.0 \%$ were taught on handing GBV in disaster situation. Knowledge on GBV was average in the staff (mean $=72.3, \mathrm{SD}=7.7$ ). There was no significant difference observed in identification, prevention and management of GBV between different employment categories of the MOH staff (all $p \mathrm{~s} \geq 0.05)$. Knowledge on GBV showed no difference between the trained and untrained $\operatorname{staff}(t(198,200)=0.8$, $p=0.4$ ) on disaster management.
\end{abstract}

Conclusions and Recommendations: Knowledge on identification, prevention and management of GBV in disaster situations among the public health staff was average, and was not sufficient. Only a minority have obtained training and all these programmes have not addressed GBV management. Thus, it is recommended to hold regular training programmes to the public health staff in GBV management in disaster situations.

Keywords: Disaster management, gender-based violence, public health staff

\section{Introduction}

Gender-based violence (GBV) is known as 'any harmful act against person's will, and that is based on socially describe difference between male and female' (1). It includes different types of violence exposures such as intimate partner violence, domestic violence, sexual abuse, forced trafficking and many others. Even though GBV encompasses considers violence exposure of both men and women, women exposure to violence is much commoner, and considered in this study.

In disaster situations, GBV is observed to be increased (2). Researchers and humanitarian workers have reported a high incidence of GBV against women in post-disaster periods $(2,3,4)$. Sexual violence is the most dangerous and immediate type of GBV reported in the acute phase of a disaster, and in the recovery and 
rehabilitation phases, other forms of GBV incidents have been reported (3). This observed tendency of GBV during crisis situation is due to many reasons such as disruption of families, loss of livelihood, displacement, isolation, stress and lack of basic needs etc. $(5,6,7)$. The breakdown of system for social and physical protection, disruption of health, education, security and other social services have also aggravated the situation. For example, after the tsunami of 2004, there were instances where women and girls were forced to trade sex for food (8). Further, unavailability of separate toilets for males and females, absence of lights in camps at night were identified as contributory factors for sexual abuse (2). All these reasons have simply made women vulnerable to violence and exploitation.

Scientifically credible estimates of the prevalence of GBV in countries after a disaster situation is low. After an earthquake in Haiti it was reported that GBV among adolescents' girls have increased from $59 \%$ to $64 \%$ (2). In Sri Lanka, even in non-disater context, there is a high prevalence of GBV $(30 \%$ $50 \%)$ reported $(9,10,11)$. Fisher (2017) conducted a qualitative study after the 2004 tsunami and found that GBV has increased after the disaster (12). However, it is difficult to get an accurate measurement of the magnitude of the problem even in well-resourced settings because the victims refuse to talk about the incidents due to many reasons.

GBV prevention and management during a disaster situation requires a multi-sectorial approach. In Sri Lanka, a major part of the responsibility falls on the public health staff as they are the ground level group who are closest to the disaster victims. The public health staff should therefore have a sound knowledge in GBV management in disaster setting. Present study was conducted to investigate the competency on identification, prevention and management of GBV in disaster situations among different public health staff workers in selected $\mathrm{MOH}$ areas in Galle district.

\section{Methods}

A descriptive cross-sectional study was conducted in Galle during September - November 2018. There are $20 \mathrm{MOH}$ areas in the Galle District, and eight were selected conveniently for the study. All the technical staff members in the $\mathrm{MOH}$ office including medical officers of health, additional medical officers of health, public health nursing sisters, supervisory public health inspectors, public health inspectors, supervisory public health midwives and public health midwives were selected for the study. Clerks, minor staff personnel and drivers were excluded as they do not actively participate in public health management in the field.

The ethical approval was obtained from the Ethics Review Committee of Postgraduate Institute of Medicine. Permission was obtained from Deputy Provincial Director of Health Services Galle and written informed consent was obtained from all participants.

\section{Measures}

Data were collected using a pre-tested selfadministrated questionnaire consisting of four sections. First section assessed the basic demographic information. The second and the third parts measured knowledge on identification and prevention of GBV in disaster situations by 10 questions each. Participants rated their knowledge on GBV on a 5-point scale ranging from 0 strongly disagree to 4 strongly agree. The final section measured knowledge on management of the GBV in disaster situation with 06 questions rated similar to the other sections ranged from 0 to 4 . The total knowledge score ranged from 0 - 104. This was categorised as poor $(0-26)$, average $(26-52)$, good $(53-78)$ and very good $(79-104)$.

\section{Statistical analysis}

Analyses were performed with SPSS (version 20 ), with two-tailed $p$-value $\leq 0.05$ considered significant. ANOVA with post hoc test was performed to assess differences in knowledge on identification, prevention and management of GBV among the four categories of the staff: medical officers (MOHH) (medical officers of health and additional medical officers of health), public health nursing sisters (PHNS), public health inspectors (PHII) (supervisory public health inspectors and public health inspectors), public health midwives (PHMM) (supervisory public health midwives and public health midwives). Independent samples ' $t$ ' test was performed to compare knowledge on identification, prevention and management of GBV between the staff who trained and untrained on disaster management. 


\section{Results}

A total of 200 public health staff members from eight $\mathrm{MOH}$ areas participated in this study. The majority of them were public health midwives (PHMM) $(\mathrm{n}=131,65.5 \%)$ and public health inspectors (PHII) $(\mathrm{n}=39,19.5 \%)$, and there were 11 $(\mathrm{n}=5.5 \%)$ medical officers $(\mathrm{MOO})$ and $7(\mathrm{n}=3.5 \%)$ public health nursing sisters (PHNSS). Most of the participants were females $(\mathrm{n}=151,75.5 \%)$. The public health staff had sufficient enough work experiences in the public health sector, with a mean of 15.2 years $(\mathrm{SD}=8.65$ years, range 0.3 36.6 years). Some of the staff members $(36.6 \%)$ reported that they had experiences in managing GBV in post-disaster situations. In the total sample, disaster management training was obtained by $23.5 \%(\mathrm{n}=47)$ but in their training, only $34.0 \%$ $(\mathrm{n}=16)$ were taught on handling GBV in disaster situations.

First, we investigated overall knowledge on handling GBV in disaster among the public health staff. In the sample, the overall knowledge was good with a mean $=77.62(\mathrm{SD}=7.73$, range $=0-104)$. PHNSS had the highest knowledge and the PHII had the poorest overall knowledge (Figure 1). To see whether the observed differences in knowledge differed with occupational categories, we conducted ANOVA with post-hoc comparison.
As shown in the Table 1, the difference in knowledge between different occupational categories were not statistically significant $(F(3,199)=0.90, p=0.44)$. The post-hoc comparison confirmed the finding $(p>0.05$ in all $)$.

Next, we examined the knowledge on identification, prevention and management of GBV among different staff categories. Knowledge on identification of GBV in the sample was average with a mean $=28.36(\mathrm{SD}=3.92$, range $=0-40)$. The MOHH had a better knowledge on identification of GBV victims in disaster situations more than the other health care workers, and the poorest knowledge was observed among PHII (Figure 1). The knowledge on prevention of GBV in disaster situation showed a mean of $31.00(\mathrm{SD}=3.78$, range =23-40). Knowledge on prevention was best among PHNSS and comparatively less among $\mathrm{MOHH}$ (32.6 and 30.5 respectively) (Figure1). Regarding GBV management in disaster situation, the mean knowledge in this subscale was $14.91(\mathrm{SD}=2.52$, range $=14-24)$. Again, the highest score was reported among PHNSS while the minimum score was reported among PHII (Figure 1). ANOVA was conducted to investigate difference in above three different components of knowledge between four different categories of the public health staff and the results showed no significant differences $(p>0.05$ in all) (Table 1$)$.

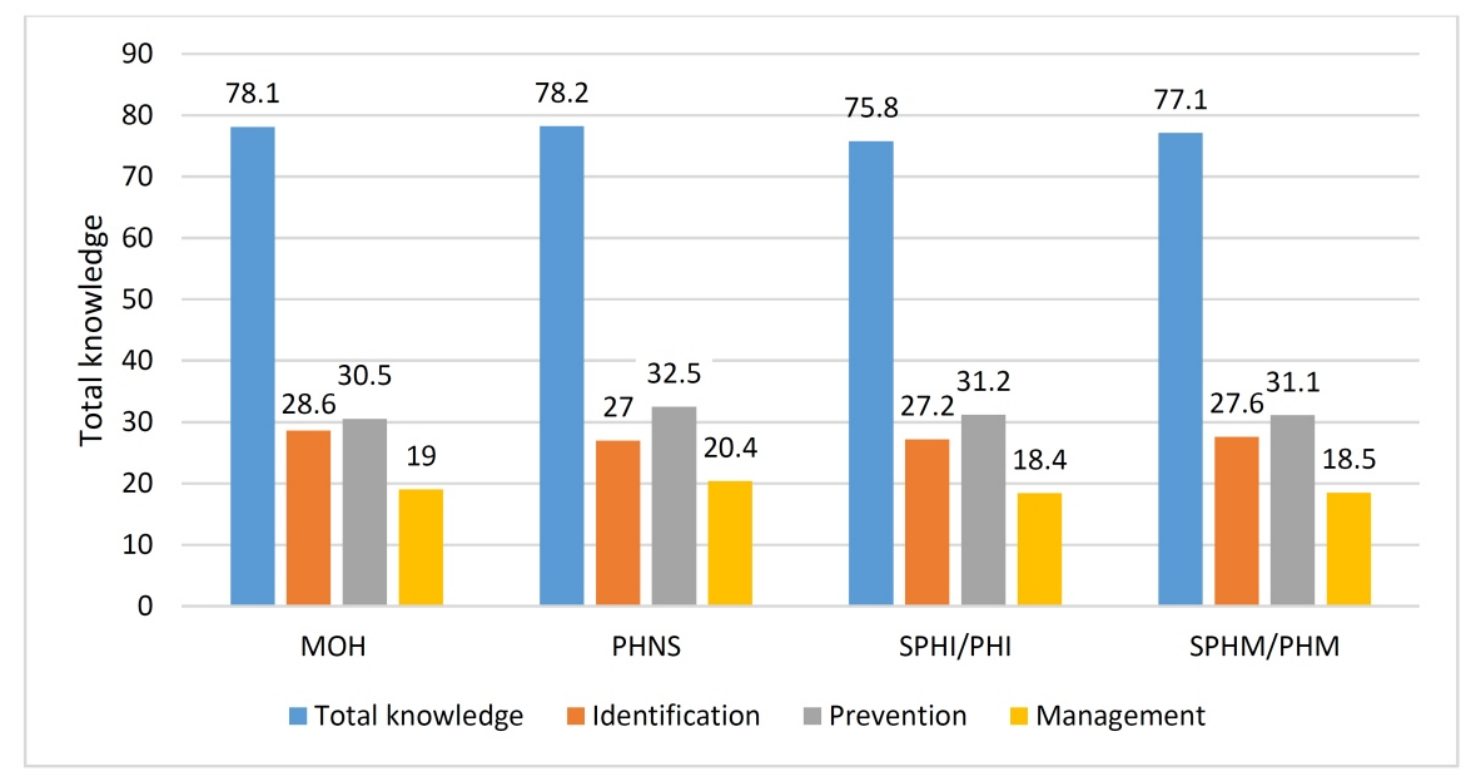

Figure 1: The mean scores of gender-based violence total knowledge, awareness, prevention and management during a disaster situation among different occupational categories of the public health staff. MOH: medical officer of health, PHNS: public health nursing sister, SPHI: supervising public health inspector, PHI: public health inspector, SPHM: supervising public health midwife, PHM: public health midwife. The total knowledge score ranged from $0-104$. 
Table 1: Descriptive statistics and ANOVA results on awareness, prevention and management of gender based violence in a disaster situation among different occupational categories in the public health system

\begin{tabular}{lccccc}
\hline $\begin{array}{l}\text { Occupational } \\
\text { category }\end{array}$ & & $\begin{array}{c}\text { Identification } \\
\text { of GBV }\end{array}$ & $\begin{array}{c}\text { Prevention } \\
\text { of GBV }\end{array}$ & $\begin{array}{c}\text { Management } \\
\text { of GBV }\end{array}$ & $\begin{array}{c}\text { Total } \\
\text { knowledge }\end{array}$ \\
\cline { 2 - 6 } & $\mathbf{N}$ & Mean (SD) & Mean (SD) & Mean (SD) & Mean (SD) \\
\hline $\mathrm{MOH}$ / AMOH & 11 & $28.6(3.7)$ & $30.5(4.8)$ & $19.1(2.2)$ & $78.2(6.0)$ \\
$\mathrm{PHNS}$ & 7 & $27.9(2.2)$ & $32.6(3.4)$ & $20.4(2.4)$ & $81.3(6.5)$ \\
$\mathrm{SPHI}$ / PHI & 42 & $27.2(3.8)$ & $31.1(4.1)$ & $18.4(2.1)$ & $76.8(7.6)$ \\
$\mathrm{SPHM}$ / PHM & 140 & $28.1(4.0)$ & $31.2(3.7)$ & $18.9(2.6)$ & $78.6(7.9)$ \\
\hline & & $\begin{array}{c}\boldsymbol{F}=\mathbf{1 . 1 2}, \\
\boldsymbol{p}=\mathbf{0 . 3 4}\end{array}$ & $\begin{array}{c}\boldsymbol{F}=\mathbf{0 . 4 7}, \\
\boldsymbol{p}=\mathbf{0 . 6 9}\end{array}$ & $\begin{array}{c}\boldsymbol{F}=\mathbf{1 . 2 9}, \\
\boldsymbol{p}=\mathbf{0 . 2 7}\end{array}$ & $\begin{array}{c}\boldsymbol{F}=\mathbf{0 . 9 0} \\
\boldsymbol{p}=\mathbf{0 . 4 4}\end{array}$ \\
\hline
\end{tabular}

GBV: Gender-based violence, MOH: medical officer of health, PHNS: public health nursing sister, SPHI: supervising public health inspector, PHI: public health inspector, SPHM: supervising public health midwife, PHM: public health midwife. Homogeneity of variance $=0.285, d f=196, p=0.836$

Table 2: Comparison of knowledge on identification, prevention and management of GBV between staff who obtained disaster management training and who had not obtained disaster management training

\begin{tabular}{|c|c|c|c|c|c|c|c|}
\hline GBV & $\begin{array}{l}\text { Training } \\
\text { obtained }\end{array}$ & $\mathbf{n}$ & Mean & SD & $t$ & df & $p$ \\
\hline \multirow[t]{2}{*}{ Identification } & Yes & 47 & 28.74 & 3.55 & \multirow{2}{*}{0.76} & \multirow{2}{*}{198} & \multirow{2}{*}{0.4} \\
\hline & No & 153 & 28.24 & 4.03 & & & \\
\hline \multirow[t]{2}{*}{ Prevention } & Yes & 47 & 31.48 & 4.39 & \multirow{2}{*}{1.00} & \multirow{2}{*}{198} & \multirow{2}{*}{0.31} \\
\hline & No & 153 & 30.85 & 3.58 & & & \\
\hline \multirow[t]{2}{*}{ Management } & Yes & 47 & 19.02 & 2.39 & \multirow{2}{*}{198} & \multirow{2}{*}{0.34} & \multirow{2}{*}{0.73} \\
\hline & No & 153 & 18.87 & 2.57 & & & \\
\hline
\end{tabular}

Notes: GBV - Gender-based violence, SD - Standard deviation, $d f$-degree of freedom, $n$ - sample size

Finally, to examine whether the disaster management training has influenced public health staff's knowledge on handling GBV, we compared the three subscales between the previously trained and untrained staff. As showed in Table 2, trained staff showed no significant improvement in knowledge compared to the untrained $\operatorname{staff}(p>0.05$ in all).
To further investigate into this aspect, we specially inquired on obtaining GBV management teaching disaster management training programme. As mentioned above, only 16 out of 47 trained participants were taught on this aspect, but the knowledge has not differed with their learning either $(t(45,47)=0.48, p=0.63)$. 


\section{Discussion}

The current study assessed the knowledge on handling gender-based violence in disaster situations in different occupational categories of public health staff in Galle district. To the best of the authors' knowledge, this is the first study that investigated public health staff's competency in handling GBV in disaster situation in Sri Lanka.

To our satisfaction, the overall knowledge on GBV handling in disaster situation in the selected public health staff was good. We observed the same in all subscales of knowledge in all occupational categories of the public health staff. The reason for this observation may be due to the fact that Galle experienced several disasters in the recent past, and some staff members have obtained training and experience in GBV management in disaster situations. For example, Galle was hard hit by the 2004 South Asian tsunami and several disaster management training programmes were conducted after the disaster. Further, most of the public health staff had good enough work experience in the field with a mean duration of 15 years. They have reported that $36.6 \%(72 / 200)$ of them have met with GBV victims during their experiences in managing disaster situations. Therefore, the public health staff of Galle may have had some training and experience in GBV management in disaster situation but still it is not adequate.

Next, we investigated the knowledge differences in total and in subscales between different occupational categories in the public health staff. Even though the ANOVA results showed no significant differences in any of the scales, some important gaps were noted. PHNSS have reported the highest overall knowledge and they scored highest in knowledge subscales on GBV prevention and management. The reason for this could be that PHNSS get compulsory training at the National Institute of Health Sciences (NIHS), Sri Lanka for one year duration and this in-service training addresses GBV and disasters management (13). MOHs had a good knowledge in GBV victim identification but not in GBV prevention or management. The reason for this could be their lack of training of GBV and disasters management as all $\mathrm{MOH} / \mathrm{AMOH}$ are meant to undergo an in-service training (Orientation on Management of Community Health for $\mathrm{MOH} / \mathrm{RE} /$ $\mathrm{MO}(\mathrm{MCH}) / \mathrm{MO}(\mathrm{PH})$ ) (13) before commencing work in the field, but not all obtain this training. Furthermore, the undergraduate medical curriculum has not addressed this topic until very recently. According to our results, PHMM had fairly good knowledge on prevention of GBV but not in victim identification. Improving PHMs' knowledge on victim identification is very much important as PHMM are the responsible persons in identifying victim in the field. PHII is the responsible officers to handle male perpetrators in GBV situations. We observed that PHII had the poorest knowledge in the total scale, and particularly in GBV victim identification and management. Both the PHMM and PHII obtain some training on GBV and disaster management in their initial training but this knowledge is not regularly updated. As ground level workers responsible for disaster and postdisaster management of victims' health, we cannot be satisfied with public health staff having an average knowledge in handling GBV during a disaster situation. We expect the public health staff to have very good knowledge in this aspect as most of the GBV cases are difficult to identify and complex to manage (14). Therefore, we believe that there is much room for improvement of their knowledge in handling GBV in disaster situations. Our recommendation is supported by another study conducted in a war affected areas in Sri Lanka. This study analysed hospital, police and welfare centre records and observed a serious lacking of awareness on GBV victim identification in both government and non-government sectors (15). Therefore, we believe that the present study will draw attention from responsible authorities to further improve public health staff's knowledge on GBV management in disaster situation.

In contrast to our expectation, only $23.5 \%$ of respondents have obtained special training in disaster management, and only $34 \%$ of them were thought on GBV management in their training. Moreover, we observed no significant knowledge difference in GBV management between disaster management trained and the untrained staff. Even though we observed good knowledge in GBV management in our sample, this finding highlights that disaster management training has not influenced their knowledge. However, the $\mathrm{MOH}$ staff may have obtained GBV management training separately from disaster management training where this study has failed to inquire. 
The important strength observed in this study is the good representation of PHII (21\%) and PHMM (70\%), who are the responsible personnel handling GBV victims in the filed in disaster situations. The main limitation we observed in this research is the less representation of MOHH and PHNSS. Selection of the study setting may also have influenced the findings. We conducted the study in Galle district, where the public health staff has experienced several disasters and obtained some training on disaster management. Therefore, caution is needed in generalising our findings.

\section{Conclusions}

Knowledge on identification, prevention and management of GBV in disaster situations among the public health staff was average and thus it is not adequate. Only a minority have obtained disaster management training and not all these training programmes have addressed GBV management in disaster situations. Thus, it is recommended to train the public health staff regularly in GBV management in disaster situations.

\section{References}

1. United Nations. Protection from sexual exploitation and abuse. New York, NK: United Nations; 2008. http://www.un.org/en/pseataskforce/overview.html

2. Torgan A. Haitians living in fear "under the tent". Atlanta, GA: CNN (website); 2012. http://www.cnn.com/ 2012/10/18/world/americans/cnnheroes-haiti-rape/

3. Interagency Standing Committee: Guidelines for gender based violence interventions in humanitarian settings. Geneva: Inter-Agency Standing Committee (IASC); 2005. https://interagencystandingcommittee.org

4. Unseen, unheard: Gender-based violence in disaster, Global study. International Federation of Red Cross and Red Crescent Societies, Geneva, 2015. Available from: www.ifrc.org

5. Buscher D. Displaced women and girls at risk: risk factors protection solutions and resource tools. New York. Women's commission for refugee woman and children; 2006. Available from: https://gsdrc.org
6. Parkinson D, Lancaster C, Stewart A. A numbers game: lack of gendered data impedes prevention of disasterrelated family violence. Health Promot J Austr. 2011; 22: $42-45$.

7. Picardo CW, Burton S, Naponick J, et al. Physically and sexually violent experiences of reproductive-aged women displaced by Hurricane Katrina. J La State Med Soc. 2010; 162(5): 284-288.

8. MacDonald R. How Women Were Affected by the Tsunami: APerspective from Oxfam. PLoS Med. 2005; 2(6): e178.

9. Jayasuriya V, Wijewardena K, Axemo P. Intimate partner violence against women in the capital province of Sri Lanka: prevalence, risk factors, and help seeking. Violence Against Women. 2011; 17(8): 1086-1102. DOI: http://doi.org/10.1177/1077801211417151.

10. Kaushalya KSS, Ponnamperuma T. Domestic violence exposure of married women in a rural area in Sri Lanka. Galle Medical Journal. 2018; 23(2): 1-8. DOI: http://doi.org/10.4038/gmj.v23i2.7975.

11. Subramaniam P, Sivayogan S. The prevalence and pattern of wife beating in the Trincomalee district in Eastern Sri Lanka. Southeast Asian Journal of Tropical Medicine and Public Health. 2001; 32(1); 186-195.

12. Fisher S. Violence Against Women and Natural Disasters: findings From Post-Tsunami Sri Lanka. Violence Against Women. 2010; 16(8): 902-918. DOI: http//doi.org/ $10.1177 / 1077801210377649$.

13. National Institute of Health Sciences (2020). Available from: http://nihs.gov.lk/nihs

14. Sloand E, Killion C, Gary FA, Dennis B, Glass N, Hassan $\mathrm{M}$, et al. Barriers and Facilitators to Engaging Communities in Gender-Based Violence Prevention following a Natural Disaster. $J$ Health Care for the Poor and Underserved. 2015 Nov; 26(4): 1377-1390. DOI: https://doi.org/10.1353/ hpu.2015.0133.

15. Wijayathilake K. Study on sexual and gender based violence in selected locations in Sri Lanka, Commissioned by The United Nations High Commissioner for Refugees, 2004. 